\title{
Ex vivo anti-malarial drugs sensitivity profile of Plasmodium falciparum field isolates from Burkina Faso five years after the national policy change
}

\author{
Halidou Tinto 1,2,3, Léa N Bonkian', Louis A Nana³, Isidore Yerbanga ${ }^{3}$, Moussa Lingani $^{3}$, Adama Kazienga ${ }^{3}$, \\ Innocent Valéa ${ }^{1,3}$, Hermann Sorgho ${ }^{2,3^{*}}$, Hervé Kpoda', Tinga Robert Guiguemdé ${ }^{1,3,4}$, Jean Bosco Ouédraogo ${ }^{1,2}$, \\ Petronella F Mens ${ }^{5}$, Henk Schallig ${ }^{5}$ and Umberto D'Alessandro 6,7
}

\begin{abstract}
Background: The recent reports on the decreasing susceptibility of Plasmodium falciparum to artemisinin derivatives along the Thailand and Myanmar border are worrying. Indeed it may spread to India and then Africa, repeating the same pattern observed for chloroquine resistance. Therefore, it is essential to start monitoring $P$. falciparum sensitivity to artemisinin derivatives and its partner drugs in Africa. Efficacy of AL and ASAQ were tested by carrying out an in vivo drug efficacy test, with an ex vivo study against six anti-malarial drugs nested into it. Results of the latter are reported here.

Methods: Plasmodium falciparum ex-vivo susceptibility to chloroquine (CQ), quinine (Q), lumefantrine (Lum), monodesethylamodiaquine (MDA), piperaquine (PPQ) and dihydroartemisinin (DHA) was investigated in children (6 months -15 years) with a parasitaemia of at least $\geq 4,000 / \mu \mathrm{l}$. The modified isotopic microtest technique was used. The results of cellular proliferation were analysed using ICEstimator software to determine the $50 \%$ inhibitory concentration (IC50) values.

Results: DHA was the most potent among the 6 drugs tested, with IC50 values ranging from $0.8 \mathrm{nM}$ to $0.9 \mathrm{nM}$ (Geometric mean IC50 $=0.8 \mathrm{nM} ; 95 \% \mathrm{Cl}[0.8-0.9]$ ). High IC50 values ranged between $0.8 \mathrm{nM}$ to $166.1 \mathrm{nM}$ were reported for lumefantrine (Geometric mean IC50 = 25.1 nM; 95\% Cl [22.4 - 28.2]). MDA and Q IC50s were significantly higher in CQ-resistant than in CQ-sensitive isolates $(P=0.0001)$. However, the opposite occurred for Lum and DHA $(\mathrm{P}<0.001)$. No difference was observed for PPQ.

Conclusion: Artemisinin derivatives are still very efficacious in Burkina Faso and DHA-PPQ seems a valuable alternative ACT. The high lumefantrine IC50 found in this study is worrying as it may indicate a decreasing efficacy of one of the first-line treatments. This should be further investigated and monitored over time with large in vivo and ex vivo studies that will include also plasma drug measurements.
\end{abstract}

\section{Background}

Artemisinin-based combination therapy (ACT) has been deployed worldwide and is currently the only available effective treatment for falciparum malaria [1-4]. Nevertheless, the recent reports on the decreasing susceptibility of Plasmodium falciparum to artemisinin derivatives along the Thailand and Myanmar border [5-8] and more

\footnotetext{
* Correspondence: hsorgho@hotmail.com

${ }^{2}$ Institut de Recherche en Sciences de la Santé/Direction Régionale de I'Ouest (IRSS/DRO), Bobo-Dioulasso, Burkina Faso

${ }^{3}$ Clinical Research Unit of Nanoro (IRSS-CRUN), Nanoro, Burkina Faso Full list of author information is available at the end of the article
}

recently in Kenya [9] are worrying. Indeed, artemisininresistant malaria parasites at the border of Thailand and Myanmar may spread to India and then Africa, repeating the same pattern observed for chloroquine resistance [10]. It is, therefore, important to document the efficacy of currently used anti-malarials and provide early warnings that would allow an adequate response and the containment of resistance [11]. It is essential to start monitoring $P$. falciparum sensitivity to artemisinin derivatives and its partner drugs in Africa. This could be done by carrying out standard in vivo drug efficacy tests

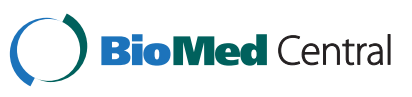

(c) 2014 Tinto et al.; licensee BioMed Central Ltd. This is an Open Access article distributed under the terms of the Creative Commons Attribution License (http://creativecommons.org/licenses/by/4.0), which permits unrestricted use, distribution, and reproduction in any medium, provided the original work is properly credited. The Creative Commons Public Domain Dedication waiver (http://creativecommons.org/publicdomain/zero/1.0/) applies to the data made available in this article, unless otherwise stated. 
recommended by the World Health Organization (WHO). In addition, considering that there are no validated molecular markers related to artemisinins [6,8], ex vivo tests may have a role as several drugs, including those in a specific ACT, can be tested at the same time [12-15].

In Burkina Faso, a new malaria treatment policy was adopted in 2005 and was fully implemented in 2006; for uncomplicated falciparum malaria, artesunate-amodiaquine (ASAQ) or alternatively artemether-lumefantrine (AL) are recommended as first-line treatments, whereas quinine is recommended for severe malaria [16]. Efficacy of AL and ASAQ were tested by carrying out an in vivo drug efficacy test, with an ex vivo study against six anti-malarial drugs nested into it. Results of the latter are reported here.

\section{Methods}

\section{Plasmodium falciparum field isolates}

The study was carried out from December 2008 to December 2010 in Bobo-Dioulasso situated at $365 \mathrm{~km}$ from Ouagadougou. The rainy season occurs from June to October (average rainfall: 1,000 $\mathrm{mm} /$ year; mean temperature $>25^{\circ} \mathrm{C}$ ) and is followed by a cold dry season from November to February (minimum temperature $15^{\circ} \mathrm{C}$ ) and a hot dry season from March to May. Malaria transmission is seasonal, from June to December. The commonest vectors are Anopheles gambiae s.s., Anopheles funestus and Anopheles arabiensis, and P. falciparum is the predominant malaria parasite [17]. All children (6 months-15 years) with fever (axillary temperature $\geq$ $37.5^{\circ} \mathrm{C}$ ) or history of fever in the last 24 hours were screened for malaria infection. Children weighing $5 \mathrm{~kg}$ or more with a $P$. falciparum mono-infection at a density between 4,000 and 200,000/ $\mu \mathrm{l}$ and haemoglobin $>7 \mathrm{~g} / \mathrm{dL}$ were included in the study if their parent/guardian provided the informed consent. Venous blood $(5-10 \mathrm{ml})$ was collected in a tube coated with EDTA (Turumo, Escap, Belgium) for ex vivo tests. This study was reviewed and approved by the Institutional Ethics Committee of Center Muraz, and was registered at ClinicalTrials.gov (ID: NCT00808951).

\section{Drugs}

The drugs tested were from the following sources: chloroquine diphosphate (Sigma Aldrich, St. Louis, USA), quinine hydrochloride (Sigma Aldrich, St. Louis, USA), lumefantrine (Novartis Pharma, Basel, Switzerland) piperaquine phosphate (Sigma Tau., Rome, Italy), the active metabolite of artemisinin, dihydroartemisinin (Sigma Tau., Rome, Italy) and the active metabolite of amodiaquine, monodeshethylamodiaquine obtained from the World Health Organization (WHO/TDR, Geneva, Switzerland). The stock solutions of chloroquine and monodesethylamodiaquine were prepared in sterile distilled water, in methanol for quinine and dihydroartemisinin, in ethanol for lumefantrine and in lactic acid for piperaquine. A three-fold serial dilution of stock solutions was made. The final concentrations ranged from $12.5 \mathrm{nM}$ to $3200 \mathrm{nM}$ for chloroquine, $7.5 \mathrm{nM}$ to $1920 \mathrm{nM}$ for monodesethylamodiaquine, $13.02 \mathrm{nM}$ to $3333 \mathrm{nM}$ for quinine, $1.25 \mathrm{nM}$ to $320 \mathrm{nM}$ for lumefantrine, $6.25 \mathrm{nM}$ to $1600 \mathrm{nM}$ for piperaquine and $0.25 \mathrm{nM}$ to $64 \mathrm{nM}$ for dihydroartemisinine. The distribution in the plates was done at $50 \mu \mathrm{l}$ per well.

\section{Ex vivo assay}

Drug sensitivity tests were performed within 24 hours of bleeding, without culture adaptation. Blood samples were washed three times in RPMI 1640 medium (Sigma Aldrich, St. Louis, USA). The modified isotopic microtest technique [14] was used. The complete RPMI 1640 medium, i.e. supplemented with $10 \%$ of human serum type AB (obtained from the blood bank of Souro Sanon University hospital, Bobo-Dioulasso, Burkina Faso), gentamicin $(10 \mu \mathrm{g} / \mathrm{ml})$ and tritiated hypoxanthine (Amersham, little Chalfont, UK), was used for parasites cultivation. Infected erythrocytes were suspended in this medium at a haematocrit of $1.5 \%$ and an initial parasitaemia between $0.1 \%$ and $0.5 \%$. This suspension was then added in quantities of $200 \mu \mathrm{l}$ per well to the plates containing the drugs. These were incubated for 48 hours at $37^{\circ} \mathrm{C}$ in $5 \% \mathrm{CO}_{2}$. After the incubation period, plates were frozen and thawed to lyse the blood cells. Cultures were then harvested (Harvester Unifilter 96, Packard) on fibre glass paper (reader plates Unifilter 96 Perkin Elmer). The strips obtained were dried and transferred to a plastic bag containing $30 \mu \mathrm{l}$ of scintillation fluid (Perkin Elmer Betaplate Scint, Wallac). The incorporation of tritiated hypoxanthine was measured using a scintillation Beta counter (Perkin Elmer Wallac MicroBeta Trilux, Turku, Finland).

\section{Data analysis and statistical methods}

For parasites growth assays, the results of cellular proliferation were expressed as counts per minute and analysed using ICEstimator software to determine the 50\% inhibitory concentration $\left(\mathrm{IC}_{50}\right)$ values [18]. The $\mathrm{IC}_{50}$ is defined as the drug concentration able to inhibit $50 \%$ of the uptake of ${ }^{3} \mathrm{H}$ hypoxanthine as compared to that measured in drug-free control wells. The threshold $\mathrm{IC}_{50}$ for ex vivo resistance was defined at $\geq 100 \mathrm{nM}$ for chloroquine, $\geq 60 \mathrm{nM}$ for monodesethylamodiaquine and $\geq$ $800 \mathrm{nM}$ for quinine $[19,20]$. The thresholds for lumefantrine, piperaquine and dihydroartemisinin are not well established yet. Data were entered in Excel version 97 and analysed using Stata version 8.0. Results were expressed as geometric mean $\mathrm{IC}_{50}$ values and the $95 \%$ confidence intervals were computed. Correlation of the $\mathrm{IC}_{50}$ values for different drugs ( 2 by 2 ) was calculated using Spearman rank-order correlation test. The activity of monodesethylamodiaquine, quinine piperaquine, 
lumefantrine and dihydroartemisinin against chloroquineresistant isolates and chloroquine-sensitive isolates were compared using the $\mathrm{IC}_{50}$ geometric means (GM). A $\mathrm{p}$ value $<0.05$ was considered statistically significant.

\section{Results}

Ex vivo susceptibility of $P$. falciparum isolates was tested for 440 samples. The culture success rate (interpretable tests) and the $\mathrm{IC}_{50}$ geometric means of the 6 drugs tested are summarized in Table 1 . The average culture success rate was around $85 \%$ (range: $79.3 \%$ - 86.8\%). Out of 382 samples successfully tested against chloroquine (Geometric mean $\mathrm{IC}_{50}=69.2 \mathrm{nM} ; 95 \% \mathrm{CI}[60.6-79.1]$ ) and quinine (Geometric mean $\mathrm{IC}_{50}=162.1 \mathrm{nM}$; 95\% CI [148.3 - 177.3]), 161 (42.1\%) were resistant to chloroquine while only 4 (1\%) were resistant to quinine. Out of 377 samples successfully tested against monodeshethylamodiaquine (Geometric mean $\mathrm{IC}_{50}=19.3 \mathrm{nM} ; 95 \% \mathrm{CI}$ [18.0 - 20.6]), $24(6.4 \%)$ were resistant. The $\mathrm{IC}_{50}$ values for lumefantrine ranged between $0.8 \mathrm{nM}$ to $166.1 \mathrm{nM}$ (Geometric mean $\mathrm{IC}_{50}=25.1 \mathrm{nM} ; 95 \%$ CI $[22.4-28.2]$ ) and that for piperaquine from $0.8 \mathrm{nM}$ to $375.2 \mathrm{nM}$ (Geometric mean $\mathrm{IC}_{50}=6.3 \mathrm{nM}$; 95\% CI [5.9 - 6.8]). Dihydroartemisinin was the most potent among the six drugs tested, with $\mathrm{IC}_{50}$ values ranging from $0.8 \mathrm{nM}$ to $0.9 \mathrm{nM}$ (Geometric mean $\mathrm{IC}_{50}=0.8 \mathrm{nM} ; 95 \%$ CI $[0.8$ 0.9]). However, three isolates had much higher $\mathrm{IC}_{50}$, i.e. $19 \mathrm{nM}, 21 \mathrm{nM}$ and $38 \mathrm{nM}$ (Figure 1).

The mean $\mathrm{IC}_{50}$ of the tested drugs were analysed by the parasites' susceptibility to chloroquine, i.e. chloroquineresistant (IC50 $\geq 100 \mathrm{nM}$ ) against chloroquine-sensitive isolates $(\mathrm{IC} 50<100 \mathrm{nM})$. Monodesethylamodiaquine and quinine $\mathrm{IC}_{50}$ mean values were significantly higher in chloroquine-resistant than in chloroquine-sensitive isolates $(\mathrm{P}=0.0001)$ (Table 2). However, the opposite occurred for lumefantrine and dihydroartemisinin; their $\mathrm{IC}_{50}$ mean values were significantly higher in chloroquinesensitive than in chloroquine-resistant isolates $(\mathrm{P} \leq 0.001)$. No difference was observed for piperaquine $(\mathrm{P}=0.382)$.
Cross-resistance between the six drugs is summarized in Table 3. A significant positive correlation (by ascending order) was found between monodeshetlyamodiaquinepiperaquine $(\mathrm{r}=0.14 ; \mathrm{P}=0.008)$, dihydroartemisinin-quinine $(\mathrm{r}=0.15 ; \mathrm{P}=0.002)$, dihydroartemisinin- piperaquine $(\mathrm{r}=0.27 ; \mathrm{P}<0.0001)$, dihydroartemisinin-lumefantrine $(\mathrm{r}=0.30 ; \mathrm{P}<0.0001)$, quinine - lumefantrine $(\mathrm{r}=0.32$; $\mathrm{P}<0.0001)$, chloroquine-quinine $(\mathrm{r}=0.51 ; \mathrm{P}<0.0001)$, monodeshetlyamodiaquine-quinine $(\mathrm{r}=0.52 ; \quad \mathrm{P}<0.0001)$ and chloroquine-monodeshetylamodiaquine $(\mathrm{r}=0.86 ; \mathrm{P}<$ $0.0001)$. For chloroquine-lumefantrine $(r=-0.10 ; \mathrm{P}=0.03)$ and monodeshetylamodiaquine-lumefantrine $(\mathrm{r}=-0.11$; $\mathrm{P}=0.02$ ) the correlation was significant but negative while for the other pair-wise comparisons no significant correlation was found.

\section{Discussion}

Since the policy change in 2005 in Burkina Faso, several studies on the therapeutic efficacy of both ASAQ and AL were carried out [21-25]. Nevertheless, the ex vivo susceptibility of $P$. falciparum to the different components of ACT had never been tested and this is the first study out of this kind. The prevalence of chloroquine resistant isolates $(\mathrm{CQR})$ was higher than that against other drugs but lower than that reported in the same area in 2006 and estimated at 50\% (Lea Bonkian, personal communication), suggesting that CQ resistance may be decreasing, possibly following the implementation of the new anti-malarial drug policy based on ACT. This is plausible when considering that a similar phenomenon has been observed in Malawi where, nine years after the withdrawn of CQ and its replacement with sulphadoxinepyrimethamine, no CQR was found [26].

Despite withdrawal of chloroquine, $\mathrm{CQR}$ could persist due to the use of treatments with similar chemical structure, resulting in a strong selective pressure [27]. The positive correlation between ex vivo $\mathrm{IC}_{50}$ values of $\mathrm{CQ}$ and MDA or quinine and between quinine and AQ indicate cross-resistance and may explain the still high prevalence of CQR found in this study. Such cross-

Table 1 Ex vivo susceptibility of Plasmodium falciparum isolates against chloroquine, monodeshethylamodiaquine, quinine, lumefantrine and dihydroartemisinin

\begin{tabular}{|c|c|c|c|c|c|}
\hline & Culture & IC50 mean $(\mathrm{nM})$ & & & Resistant \\
\hline & $\begin{array}{c}\text { success rate } \\
\%(n / N)\end{array}$ & {$[95 \% \mathrm{Cl}]$} & Minimum & Maximum & \\
\hline Chloroquine & $86.8(382 / 440)$ & $69.2[60.6-79.1]$ & 8.3 & 595.9 & $161(42.1)$ \\
\hline Quinine & $86.8(382 / 440)$ & $162.1[148.3-177.3]$ & 10.2 & 950.3 & $4(1.0)$ \\
\hline Monodesethylamodiaquine & $85.7(377 / 440)$ & $19.3[18.0-20.6]$ & 0.8 & 595.9 & $24(6.4)$ \\
\hline Lumefantrine & $86.8(382 / 440)$ & $25.1[22.4-28.2]$ & 0.8 & 166.1 & NA \\
\hline Piperaquine & $79.3(349 / 440)$ & $6.3[5.9-6.8]$ & 0.8 & 375.2 & NA \\
\hline Dihydroartemisinin & $86.5(381 / 440)$ & $0.8[0.8-0.9]$ & 0.1 & 38.8 & NA \\
\hline
\end{tabular}




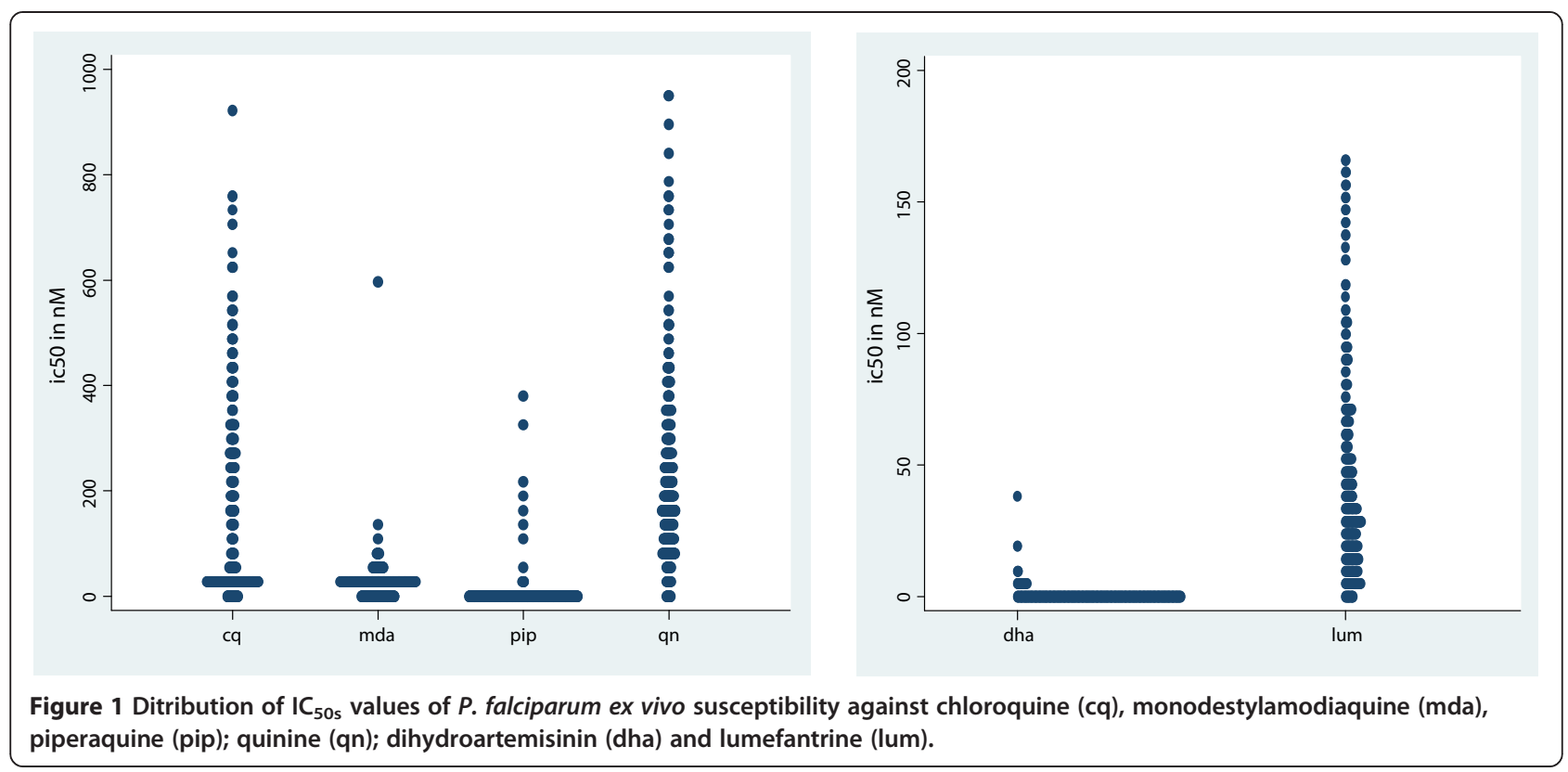

resistance is not surprising as it has already been reported by several studies $[20,28,29]$. Nevertheless, the relationship between $\mathrm{CQ}$ and $\mathrm{AQ}$ efficacy is not a straightforward one as AQ may still be effective where CQ resistance is high [1,30-32]. This seems confirmed by the low prevalence of AQ resistant isolates as determined by our ex vivo test. Nevertheless, almost half of the isolates had AQ $\mathrm{IC}_{50}$ values higher than $20 \mathrm{nM}$, a relatively high figure when considering that in Cameroun most isolates of recurrent infection after $\mathrm{AQ}$ treatment had $\mathrm{IC}_{50}$ ranging between 25.6 and $115 \mathrm{nM}$, indicating that the threshold for AQ resistance might be lower than the standard value of $\geq 60 \mathrm{nM}$ [19]. This raises the issue of defining appropriate drugs' ex vivo $\mathrm{IC}_{50}$ thresholds able to predict in vivo outcomes [19,27,33,34].

In the new malaria treatment policy adopted in Burkina Faso, quinine is still the recommended treatment for severe malaria and for any treatment failure after administration of ASAQ or AL [16]. Only 4 isolates were found to be resistant to quinine, an extremely low prevalence when considering the potentially frequent use of this drug and cross resistance with $\mathrm{CQ}$. Lowering the threshold for resistance to $600 \mathrm{nM}[28,35,36]$, increased the number of isolates classified as resistant but their prevalence remains low, i.e. 4\% (17/382). Therefore, quinine can still be considered effective in Burkina Faso though recent reports of an increasing number of patients with recurrent infection after ACT treatment $[21,24]$ may result in the frequent use of quinine as rescue treatment and higher drug pressure. There is the need of regularly monitoring the susceptibility of local isolates to quinine for the early detection of quinine resistance.

The resistance threshold for lumefantrine is not established yet but the mean $\mathrm{IC}_{50}(25.1 \mathrm{nM})$ found in this study seems high compared to that $(9.8 \mathrm{nM})$ reported by a study carried out in Senegal at approximately the same period [37]. Similarly, in Cameroon the mean $\mathrm{IC}_{50}$ for lumefantrine was $11.9 \mathrm{nM}$ in 1997 and $9.57 \mathrm{nM}$ in 2003 [38]. Therefore, high lumefantrine $\mathrm{IC}_{50}$ may indicate a decreasing susceptibility of local isolates to this drug, though baseline data are not available, possibly explained by the high AL use and hence drug pressure in this urban area. Indeed, though Burkina Faso has adopted two types of ACT as first-line treatments, ASAQ is

Table 2 Ex vivo $I_{50}$ of Plasmodium falciparum isolates against monodeshethylamodiaquine, quinine, lumefantrine, piperaquine and dihydroartemisinin by chloroquine susceptibility

\begin{tabular}{lccc}
\hline Drug & Chloroquine-resistant isolates $(\mathbf{n}=\mathbf{1 6 1})$ & Chloroquine-sensitive isolates $(\mathbf{n}=\mathbf{2 2 1})$ & $\mathbf{P}$ value \\
\hline Chloroquine & $289.8[269.2-312.0)]$ & $24.4(22.8-26.1)$ & 0.0001 \\
Monodesethylamodiaquine & $33.8[31.4-36.4]$ & $12.8[12.0-13.6]$ & 0.0001 \\
Quinine & $249.7[223.3-279.1]$ & $120.4[107.2-135.2]$ & 0.0001 \\
Lumefantrine & $21.9[18.8-25.5]$ & $27.8[23.5-32.8]$ & 0.0006 \\
Piperaquine & $6.5[5.7-7.3]$ & $6.1[5.6-6.7]$ & 0.382 \\
Dihydroartemisinin & $0.7[0.6-0.8]$ & $0.9[0.8-1.0]$ & 0.001 \\
\hline
\end{tabular}


Table 3 Pairwise comparison of ex vivo $\mathrm{IC}_{50}$ values

\begin{tabular}{lcc}
\hline Drug pairs & $\mathbf{r}^{*}$ & $\boldsymbol{P}$ - value \\
\hline Chloroquine - Dihydroartemisinin & -0.08 & 0.09 \\
Chloroquine - Monodestylamodiaquine & 0.86 & $<0.0001$ \\
Chloroquine - quinine & 0.51 & $<0.0001$ \\
Chloroquine - Piperaquine & 0.02 & 0.63 \\
Chloroquine - Lumefantrine & -0.10 & 0.03 \\
Dihydroartemisinin- Monodestylamodiaquine & 0.01 & 0.77 \\
Dihydroartemisinin - Quinine & 0.15 & 0.002 \\
Dihydroartemisinin- Piperaquine & 0.27 & $<0.0001$ \\
Dihydroartemisinin - Lumefantrine & 0.30 & $<0.0001$ \\
Monodestylamodiaquine - Quinine & 0.52 & $<0.0001$ \\
Monodestylamodiaquine - Piperaquine & 0.14 & 0.008 \\
Monodestylamodiaquine - Lumefantrine & -0.11 & 0.025 \\
Quinine - Piperaquine & 0.07 & 0.16 \\
Quinine - Lumefantrine & 0.32 & $<0.0001$ \\
Piperaquine - Lumefantrine & 0.04 & 0.35 \\
\hline
\end{tabular}

${ }^{*}$ Spearman's rank-order correlation coefficient (r).

mainly used in rural areas while AL in towns, including Bobo-Dioulasso where this study was carried out. This is also confirmed by informal discussions with local health practitioners who stated that they mostly prescribe AL for uncomplicated malaria. However, such hypotheses need to be confirmed by a well-planned survey. The high lumefantrine $\mathrm{IC}_{50}$ could also be due to technical problems related to the execution of the ex vivo test. Indeed, lumefantrine is an amino alcohol and the drugs in this class are not easily soluble, a characteristic that may compromise the reproducibility of ex vivo test results [39]. Nevertheless, the use of the ethanol as solvent in this study should have addressed this problem so that a major bias related to the lumefantrine solubility is unlikely.

Dihydroartemisinin-piperaquine is one of the most recent ACT submitted for prequalification to the WHO [40] and represents an additional ACT for endemic countries, including Burkina Faso. Mean piperaquine $\mathrm{IC}_{50}$ was extremely low, only two isolates had values above $200 \mathrm{nM}$, and similar to that observed in Uganda [41]. These results contrast with those found in Cameroon and Kenya, where the mean piperaquine $\mathrm{IC}_{50}$ was $39 \mathrm{nM}$ and $50 \mathrm{nM}$, respectively [42,43]. In addition, there was no correlation between piperaquine and chloroquine, lumefantrine and quinine $\mathrm{IC}_{50} \mathrm{~s}$, a weak correlation with $\mathrm{MDA}$, and piperaquine was equally active on both CQ sensitive and resistant isolates. All these elements support the use of dihydroartemisinin-piperaquine as an alternative $\mathrm{ACT}$ in Burkina Faso.

The mean dihydroartemisinin $\mathrm{IC}_{50}$ was extremely low, indicating high susceptibility of local isolates, and in accordance with other studies carried out in sub-Saharan
Africa $[36,38,44]$. In addition, dihydroartemisinin $\mathrm{IC}_{50}$ was not correlated to that of MDA while the correlation with CQ $\mathrm{IC}_{50}$ was a negative one, also shown by its higher activity against CQ resistant isolates as compared to sensitive ones. This is reassuring when considering the threat represented by the emergence of artemisinin resistance in South-East Asia where, besides a delay in parasite clearance, the ex vivo sensitivity of $P$. falciparum to artemisinin derivatives has declined substantially over the last few years $[2,4-6,8,45,46]$, reaching in some regions mean $\mathrm{IC}_{50}$ values as high $21.2 \mathrm{nM}$ for dihydroartemisinin and $16.3 \mathrm{nM}$ for artesunate [47]. Nevertheless, the interpretation of this results should also consider the weaknesses of the standard ex vivo tests, e.g. the $3 \mathrm{H}$ hypoxantine technique, in detecting artemisinin derivatives resistance [48]. Though in sub-Saharan Africa the ex vivo efficacy of artemisinin derivatives seems high, declining in vivo responsiveness of $P$. falciparum infections to ACT has been observed in Kenya [9].

\section{Conclusion}

In conclusion, this study confirms that artemisinin derivatives are still very efficacious and dihydroartemisininpiperaquine seems a valuable alternative ACT in Burkina Faso. Similarly, both quinine and amodiaquine had a good sensitivity profile. The high lumefantrine $\mathrm{IC}_{50}$ found in this study is worrying as it may indicate a decreasing efficacy of one the first line treatments. This should be further investigated and monitored over time with large in vivo and ex vivo studies that will include also plasma drug measurements.

\section{Competing interest}

The authors declare that they have no competing interests.

\section{Authors' contribution}

The study was conceived by HT, UDA, PFM and HS in the framework of the MALACTRES project. It was conducted in the field by HT, NLB, LAN, IY, ML IV, $\mathrm{HS}$ and HK and supervised by JBO and TRG. Data analysis was done by AK, IV and HT. The manuscript was drafted by HT and UDA. All authors read and approved the final manuscript.

\section{Acknowledgements}

We thank the parents of the children included in this study for their participation. Many thanks to the health staff of Dafra Health Distrcit Hospital and Centre Muraz parasitology laboratory team for their collaboration. This study was monitored by the Clinical Trial Unit of the Institute of Tropical Medicine, Antwerp, Belgium. Thanks go also to Raffaella Ravinetto, head of the Clinical Trial Unit of the Institute of Tropical Medicine, Antwerp, Belgium, for her inputs to the manuscript.

\section{Financial support}

This study was funded by the European Union Framework Program 7 (FP7) through the grant attributed to the MALACTRES Project (www.malactres.eu)

\section{Author details}

${ }^{1}$ Unité de Recherche sur le Paludisme et Maladies Tropicales Négligées, Centre Muraz, Bobo-Dioulasso, Burkina Faso. ${ }^{2}$ Institut de Recherche en Sciences de la Santé/Direction Régionale de l'Ouest (IRSS/DRO), Bobo-Dioulasso, Burkina Faso. ${ }^{3}$ Clinical Research Unit of Nanoro (IRSS-CRUN), Nanoro, Burkina Faso. ${ }^{4}$ Institut Supérieur des Sciences de la Santé (INSSA), 
Bobo Dioulasso, Burkina Faso. ${ }^{5}$ Royal Tropical Institute/Koninklijk Instituut voor de Tropen (KIT), Amsterdam, The Netherlands. ${ }^{6}$ Medical Research Council Unit, The Gambia, Disease Control \& Elimination Theme, Fajara, The Gambia. ${ }^{7}$ Prince Leopold Institute of Tropical Medicine, Antwerp, Belgium.

Received: 2 April 2014 Accepted: 21 May 2014

Published: 31 May 2014

\section{References}

1. Zwang J, Olliaro P, Barennes H, Bonnet M, Brasseur P, Bukirwa H, Cohuet S, D'Alessandro U, Djimdé A, Karema C, Guthmann JP, Hamour S, Ndiaye JL, Mårtensson A, Rwagacondo C, Sagara I, Same-Ekobo A, Sirima SB, Van Den Broek I, Yeka A, Taylor WR, Dorsey G, Randrianarivelojosia M: Efficacy of artesunate-amodiaquine for treating uncomplicated falciparum malaria in sub-Saharan Africa: a multi-centre analysis. Malar J 2009, 8:203.

2. World Health Organization: Containment of Malaria Multi-Drug Resistance on the Cambodia-Thailand Border. Switzerland, Geneva: Report of an Informal Consultation Phnom Penh; 2007:23.

3. World Health Organization: Guidelines for the Treatment of Malaria. 2nd edition. Switzerland, Geneva: WHO; 2010:166.

4. Maude RJ, Pontavornpinyo W, Saralamba S, Aguas R, Yeung S, Dondorp AM, Day NPJ, White NJ, White LJ: The last man standing is the most resistant: eliminating artemisinin-resistant malaria in Cambodia. Malar J 2009, 8:31.

5. Rogers WO, Sem R, Tero T, Chim P, Lim P, Muth S, Socheat D, Ariey F, Wongsrichanalai $C$ : Failure of artesunate-mefloquine combination therapy for uncomplicated Plasmodium falciparum malaria in southern Cambodia. Malar J 2009, 8:10.

6. Noedl H, Se Y, Sriwichai S, Schaecher K, Teja-Isavadharm P, Smith B, Rutvisuttinunt W, Bethell D, Surasri S, Fukuda MM, Socheat D, Chan Thap L: Artemisinin resistance in Cambodia: a clinical trial designed to address an emerging problem in Southeast Asia. Clin Infect Dis 2010, 51:82-89.

7. Lim P, Alker AP, Khim N, Shah NK, Incardona S, Doung S, Yi P, Bouth DM Bouchier C, Puijalon OM, Meshnick SR, Wongsrichanalai C, Fandeur T, Le Bras J, Ringwald P, Ariey F: Pfmdr1 copy number and arteminisin derivatives combination therapy failure in falciparum malaria in Cambodia. Malar J 2009, 8:11.

8. Dondorp AM, Nosten F, Yi P, Das D, Phyo AP, Tarning J, Lwin KM, Ariey F, Hanpithakpong W, Lee SJ, Ringwald P, Silamut K, Imwong M, Chotivanich K, Lim P, Herdman T, An SS, Yeung S, Singhasivanon P, Day NP, Lindegardh N, Socheat $\mathrm{D}$, White NJ: Artemisinin resistance in Plasmodium falciparum malaria. N Engl J Med 2009, 361:455-467.

9. Borrmann S, Sasi P, Mwai L, Bashraheil M, Abdallah A, Muriithi S, Frühauf $H$, Schaub B, Pfeil J, Peshu J, Hanpithakpong W, Rippert A, Juma E, Tsofa B, Mosobo M, Lowe B, Osier F, Fegan G, Lindegårdh N, Nzila A, Peshu N, Mackinnon M, Marsh K: Declining responsiveness of Plasmodium falciparum infections to artemisinin-based combination treatments on the Kenyan coast. PLOS ONE 2011, 6:e26005.

10. Gharbi M, Flegg JA, Hubert V, Kendjo E, Metcalf JE, Bertaux L, Guérin PJ, Le Bras J, Aboubaca A, Agnamey P, Angoulvant A, Barbut P, Basset D, Belkadi G, Bellanger AP, Bemba D, Benoit-Vica F, Berry A, Bigel ML, Bonhomme J, Botterel F, Bouchaud O, Bougnoux ME, Bourée P, Bourgeois N, Branger C, Bret L, Buret B, Casalino E, Chevrier $S$, et al: Longitudinal study assessing the return of chloroquine susceptibility of Plasmodium falciparum in isolates from travellers returning from West and Central Africa, 2000-2011. Malar I 2013, 12:35.

11. Sibley $\mathrm{CH}$, Guerin PJ, Ringwald P: Monitoring antimalarial resistance: launching a cooperative effort. Trends Parasitol 2010, 26:221-224.

12. Anderson T: Mapping the spread of malaria drug resistance. PLoS Med 2009, 6:2

13. Wongsrichanalai C, Pickard AL, Wernsdorfer WH, Meshnick SR: Epidemiology of drug-resistant malaria. Lancet Infect Dis 2002, 2:209-218

14. Desjardins RE, Canfield CJ, Haynes JD, Chulay JD: Quantitative assessment of antimalarial activity in vitro by a semiautomated microdilution technique. Antimicrob Agents Chemother 1979, 16:710-718.

15. Shretta R, Omumbo J, Rapuoda B, Snow RW: Using evidence to change antimalarial drug policy in Kenya. Trop Med Int Health 2000, 5:755-764.

16. Gansané A, Nébié I, Soulama I, Tiono A, Diarra A, Konaté AT, Ouédraogo A, Sirima BS: Change of antimalarial first-line treatment in Burkina Faso in 2005. Bull Soc Pathol Exot 2009, 102:31-35.

17. Tinto H, Zoungrana EB, Coulibaly SO, Ouedraogo JB, Traoré M, Guiguemde TR, Van Marck E, D'Alessandro U: Chloroquine and sulphadoxine- pyrimethamine efficacy for uncomplicated malaria treatment and haematological recovery in children in Bobo-Dioulasso, Burkina Faso during a 3-year period 1998-2000. Trop Med Int Health 2002, 7:925-930.

18. ICEstimator software. http://www.antimalarial-icestimator.net, Version 1.

19. Basco LK, Ndounga M, Keundjian A, Ringwald P: Molecular epidemiology of malaria in cameroon. IX. Characteristics of recrudescent and persistent Plasmodium falciparum infections after chloroquine or amodiaquine treatment in children. Am J Trop Med Hyg 2002, 66:117-123.

20. Ringwald P, Meche FS, Bickii J, Basco LK: In Vitro culture and drug sensitivity assay of Plasmodium falciparum with nonserum substitute and acute-phase sera. J Clin Microbiol 1999, 37:700-705.

21. Four T: A head-to-head comparison of four artemisinin-based combinations for treating uncomplicated malaria in African children: a randomized trial. PLoS Med 2011, 8:e1001119.

22. Siribié M, Diarra A, Tiono AB, Soulama I, Sirima SB: Efficacité de l'artéméther-luméfantrine dans le traitement du paludisme simple de l'enfant en milieu rural au Burkina Faso en 2009. Bull Soc Path Exot 2012 105:202-207.

23. Zongo I, Dorsey G, Rouamba N, Dokomajilar C, Séré Y, Rosenthal PJ, Ouédraogo JB: Randomized comparison of amodiaquine plus sulfadoxine-pyrimethamine, artemether-lumefantrine, and dihydroartemisinin-piperaquine for the treatment of uncomplicated Plasmodium falciparum malaria in Burkina Faso. Clin Infect Dis 2007. 45:1453-1461

24. Zongo I, Dorsey G, Rouamba N, Tinto H, Dokomajilar C, Guiquemde RT, Rosenthal PJ, Ouedraogo JB: Artemether-lumefantrine versus amodiaquine plus sulfadoxine-pyrimethamine for uncomplicated falciparum malaria in Burkina Faso: a randomised non-inferiority trial. Lancet 2007, 369:491-498.

25. Barennes H, Nagot N, Valea I, Koussoubé-Balima T, Ouedraogo A, Sanou T, Yé S: A randomized trial of amodiaquine and artesunate alone and in combination for the treatment of uncomplicated falciparum malaria in children from Burkina Faso. Trop Med Int Health 2004, 9:438-444.

26. Kublin JG, Cortese JF, Njunju EM, Mukadam RAG, Wirima JJ, Kazembe PN, Djimdé AA, Kouriba B, Taylor TE, Plowe CV: Reemergence of chloroquinesensitive Plasmodium falciparum malaria after cessation of chloroquine use in Malawi. J Infect Dis 2003, 187:1870-1875.

27. Tinto H, Rwagacondo C, Karema C, Mupfasoni D, Vandoren W, Rusanganwa E, Erhart A, Van Overmeir C, Van Marck E, D'Alessandro U: In-vitro susceptibility of Plasmodium falciparum to monodesethylamodiaquine, dihydroartemisinin and quinine in an area of high chloroquine resistance in Rwanda. Trans R Soc Trop Med Hyg 2006, 100:509-514.

28. Ouédraogo JB, Dutheil Y, Tinto H, Traoré B, Zampa H, Tall F, Coulibaly SO, Guiquemdé TR: In vitro sensitivity of Plasmodium falciparum to halofantrine compared with chloroquine, quinine and mefloquine in the region of Bobo-Dioulasso, Burkina Faso (West Africa). Trop Med Int Health 2003, 3:159-164

29. Pradines B, Tall A, Parzy D, Spiegel A, Fusai T, Hienne R, Trape JF, Doury JC: In-vitro activity of pyronaridine and amodiaquine against African isolates (Senegal) of Plasmodium falciparum in comparison with standard antimalarial agents. J Antimicrob Chemother 1998, 42:333-339.

30. Gorissen E, Ashruf G, Lamboo M, Bennebroek J, Gikunda S, Mbaruku G, Kager PA: In vivo efficacy study of amodiaquine and sulfadoxine/ pyrimethamine in Kibwezi, Kenya and Kigoma, Tanzania. Trop Med Int Health 2000, 5:459-463.

31. Brasseur P, Guiguemde R, Diallo S, Guiyedi V, Kombila M, Ringwald P, Olliaro $P$ : Amodiaquine remains effective for treating uncomplicated malaria in west and central Africa. Trans R Soc Trop Med Hyg 1999, 93:645-650.

32. Staedke SG, Kamya MR, Dorsey G, Gasasira A, Ndeezi G, Charlebois ED, Rosenthal PJ: Amodiaquine, sulfadoxine/pyrimethamine, and combination therapy for treatment of uncomplicated falciparum malaria in Kampala, Uganda: a randomised trial. Lancet 2001, 358:368-374.

33. White $\mathrm{NJ}$ : Why is it that antimalarial drug treatments do not always work? Ann Trop Med Parasitol 1998, 92:449-458.

34. Aubouy A, Mayombo J, Keundjian A, Bakary M, Le Bras J, Deloron P. Short report: lack of prediction of amodiaquine efficacy in treating Plasmodium falciparum malaria by in vitro tests. Am J Trop Med Hyg 2004, 71:294-296.

35. Pettinelli F, Pettinelli M-E, Eldin De Pécoulas P, Millet J, Michel D, Brasseur P, Druilhe P: Short report: high prevalence of multidrug-resistant Plasmodium falciparum malaria in the French territory of Mayotte. Am J Trop Med Hyg 2004, 70:635-637. 
36. Fall B, Diawara S, Sow K, Baret E, Diatta B, Fall KB, Mbaye PS, Fall F, Diémé $Y$, Rogier C, Wade B, Bercion R, Pradines B: Ex vivo susceptibility of Plasmodium falciparum isolates from Dakar, Senegal, to seven standard anti-malarial drugs. Malar J 2011, 10:310.

37. Fall B, Pascual A, Sarr FD, Wurtz N, Richard V, Baret E, Diémé Y, Briolant $S$, Bercion R, Wade B, Tall A, Pradines B: Plasmodium falciparum susceptibility to anti-malarial drugs in Dakar, Senegal, in 2010: an ex vivo and drug resistance molecular markers study. Malar J 2013, 12:107.

38. Basco LK, Ringwald P: Molecular epidemiology of malaria in Cameroon. XXIV. Trends of in vitro antimalarial drug responses in Yaounde, Cameroon. Am J Trop Med Hyg 2007, 76:20-26.

39. Fule R, Meer T, Ajay Sav AP: Solubility and dissolution rate enhancement of lumefantrine using hot melt extrusion technology with physicochemical characterisation. J Pharm Investig 2013, 43:305-321.

40. World Health Organization: WHO Technical Report Series (UNEDITED REPORT). Switzerland, Geneva: WHO; 2011:193.

41. Nsobya SL, Kiggundu M, Nanyunja S, Joloba M, Greenhouse B, Rosenthal PJ: In vitro sensitivities of Plasmodium falciparum to different antimalarial drugs in Uganda. Antimicrob Agents Chemother 2010, 54:1200-1206.

42. Basco LKRP: In vitro activity of piperaquine and other 4- aminoquinolines against clinical isolates of Plasmodium falciparum in Cameroon. Antimicrob Agents Chemother 2003, 47:1391-1394.

43. Mwai L, Kiara SM, Abdirahman A, Pole L, Rippert A, Diriye A, Bull P, Marsh K, Borrmann S, Nzila A: In vitro activities of piperaquine, lumefantrine, and dihydroartemisinin in Kenyan Plasmodium falciparum isolates and polymorphisms in pfcrt and pfmdr1. Antimicrob Agents Chemother 2009, 53:5069-5073.

44. Pascual A, Parola P, Benoit-Vical F, Simon F, Malvy D, Picot S, Delaunay P, Basset D, Maubon D, Faugère B, Ménard G, Bourgeois N, Oeuvray C, Didillon $E$, Rogier CPB: Ex vivo activity of the ACT new components pyronaridine and piperaquine in comparison with conventional ACT drugs against isolates of Plasmodium falciparum. Malar J 2012, 11:9.

45. Na-Bangchang K, Ruengweerayut R, Mahamad P, Ruengweerayut K, Chaijaroenkul W: Declining in efficacy of a three-day combination regimen of mefloquine-artesunate in a multi-drug resistance area along the Thai-Myanmar border. Malar J 2010, 9:273.

46. Woitsch B, Wernsdorfer G, Congpuong K, Rojanawatsirivet C, Sirichaisinthop J, Wernsdorfer WH: Sensitivity to artemisinin, mefloquine and quinine of Plasmodium falciparum in northwestern Thailand. Wien Klin Wochenschr 2007, 122 Suppl(19-20 Suppl 3):76-82.

47. Pradines B, Bertaux L, Pomares C, Delaunay P, Marty P: Reduced in vitro susceptibility to artemisinin derivatives associated with multi-resistance in a traveller returning from South-East Asia. Malar J 2011, 10:268.

48. Witkowski B, Amaratunga C, Khim N, Sreng S, Chim P, Kim S, Lim P, Mao S, Sopha C, Sam B, Anderson JM, Duong S, Chuor CM, Taylor WRJ, Suon S, Mercereau-Puijalon O, Fairhurst RM, Menard D: Novel phenotypic assays for the detection of artemisinin-resistant Plasmodium falciparum malaria in Cambodia: in-vitro and ex-vivo drug-response studies. Lancet Infect Dis 2013, 13:1043-1049.

doi:10.1186/1475-2875-13-207

Cite this article as: Tinto et al: Ex vivo anti-malarial drugs sensitivity profile of Plasmodium falciparum field isolates from Burkina Faso five years after the national policy change. Malaria Journal 2014 13:207.

\section{Submit your next manuscript to BioMed Central and take full advantage of:}

- Convenient online submission

- Thorough peer review

- No space constraints or color figure charges

- Immediate publication on acceptance

- Inclusion in PubMed, CAS, Scopus and Google Scholar

- Research which is freely available for redistribution 